\title{
Assessment of Apical Periodontitis by MRI: A Feasibility Study
}

\section{Vergleich von MRT und DVT bei der Diagnose von periapikalen Osteolysen}

\author{
Authors \\ M. A. Geibel ${ }^{1}$, E. S. Schreiber ${ }^{2}$, A. K. Bracher ${ }^{2}$, E. Hell ${ }^{3}$, J. Ulrici ${ }^{3}$, L. K. Sailer ${ }^{4}$, Y. Ozpeynirci ${ }^{5}$, V. Rasche ${ }^{2}$ \\ Affiliations \\ Oral and Maxillofacial Surgery, Ulm University, Ulm \\ 2 Internal Medicine II, Ulm University, Ulm, Germany \\ Dental Imaging, Sirona Dental Systems GmbH, Bensheim, Germany \\ 4 MKG, DOC Praxisklinik im Wiley, Neu-Ulm, Germany \\ Diagnostic and Interventional Radiology, Ulm University, Ulm, Germany
}

Key words
head/neck
diagnostic radiology
MR imaging
radiography
apical periodontitis
dental MRI
cone beam computed
tomography

received 20.5.2014 accepted $\quad 5.11 .2014$

\section{Bibliography}

DOI http://dx.doi.org/

10.1055/s-0034-1385808

Published online: 16.1.2015

Fortschr Röntgenstr 2015; 187:

269-275 @ Georg Thieme

Verlag KG Stuttgart • New York .

ISSN 1438-9029

\section{Correspondence}

Frau Prof. Margit-Ann Geibel

Zahnheilkunde, Universität Ulm

Albert-Einstein-Allee 11

89081 Ulm

Germany

Tel: ++ 49/0731/50064303

Fax: ++49/0731/50064302

margrit-ann.geibel@

uniklinik-ulm.de

\section{Zusammenfassung \\ $\nabla$}

Ziel: Das Ziel dieser klinischen Machbarkeitsstudie war die Untersuchung der Darstellbarkeit periapikaler Osteolysen mittels der Magnetresonanztomografie (MRT) im direkten Vergleich mit der digitalen Volumentomografie (DVT).

Material und Methoden: In die Studie wurden 19 Patienten (Durchschnittsalter $43 \pm 13$ Jahre) mit 34 periapikalen Osteolysen eingeschlossen. Die Läsionen wurden radiologisch befundet als periapikale Osteolysen (DVT) oder als knöcherne Destruktion in der Spongiosa (MRT), die eine Lagebeziehung zum Apex des Wurzelkanals hatten und mindestens eine Ausdehnung der zweifachen Größe des parodontalen Ligaments zeigten. Zur Auswertung kamen die Lage der Läsion und deren räumliche Ausdehnung im direkten Vergleich der Darstellung mittels MRT und DVT.

Ergebnisse: Bei der Beschreibung der apikalen Läsionen war die Darsellung mittels DVT technikbedingt beschränkt auf die Zähne und rein knöcherne Befunde. Mittels der MRT konnte zusätzlich eine Darstellung des Weichteilgewebes erreicht werden. Die Darstellung im MRT erlaubte eine zufriedenstellende radiologische Diagnostik. Zusäzlich konnten Unterschiede im Aufbau der Mukosa und auch von soliden Einschlüssen differenziert werden. Alle mittels DVT identifzierten periapikalen Läsionen, wurden auch mittels MRT diagnostiziert. Die Daten vom MRT und DVT zeigten eine gute Korrelationen, wobei die Ausdehnung der Läsionen in der MRT Darstellung leicht, aber statistisch signifikant vergrößert resultierte. Bei mehreren Patienten wurden in der T2w Darstellung heterogene Läsionen gefunden und bei vier Patienten zeigte sich ein scharf begrenztes hyperintenses Signal in der Nähe des apikalen Foramens.

Schlussfolgerung: Die Beurteilung des Weichgewebes und eventueller Einschlüsse mittels MRI können helfen die radiologische Diagnose einer apikalen Aufhellung weiter zu differenzieren. Die

\section{Abstract \\ $\nabla$}

Purpose: The purpose of this clinical feasibility study was to evaluate the applicability of magnetic resonance imaging (MRI) for the assessment of apical periodontitis in direct comparison with cone beam CT (CBCT).

Materials and Methods: 19 consecutive patients (average age $43 \pm 13$ years) with 34 lesions in total (13 molars, 14 premolars and 7 front teeth) were enrolled in this feasibility study. Periapical lesions were defined as periapical radiolucencies (CBCT) or structural changes in the spongy bone signal (MRI), which were connected with the apical part of a root and with at least twice the width of the periodontal ligament space. The location and dimension of the lesions were compared between MRI and CBCT.

Results: While mainly mineralized tissue components such as teeth and bone were visible with CBCT, complimentary information of the soft tissue components was assessable with MRI. The MRI images provided sufficient diagnostic detail for the assessment of the main structures of interest. Heterogeneous contrast was observed within the lesion, with often a clear enhancement close to the apical foramen and the periodontal gap. No difference for lesion visibility was observed between MRI and CBCT. The lesion dimensions corresponded well, but were slightly but significantly overestimated with MRI. A heterogeneous lesion appearance was observed in several patients. Four patients presented with a well circumscribed hyperintense signal in the vicinity of the apical foramen.

Conclusion: The MRI capability of soft tissue characterization may facilitate detailed analysis of periapical lesions. This clinical study confirms the applicability of multi-contrast MRI for the identification of periapical lesions. 
Studie indiziert den sinnvollen Einsatz der multi-kontrast MRT für die Identifizierung apikaler Osteolysen.

Kernaussagen:

- Die MRT erlaubt die Erkennung periapikaler Läsionen ohne Strahlenexposition.

- Der Mehrwert der MRT erscheint in der Möglichkeit präoperative apikale Osteolysen zu charakterisieren.

- Die MRT hat das Potential die Läsionsdimensionen genauer zu identifizieren.
Key Points:

- MRI can be applied for the identification of periapical lesions without ionizing radiation exposure

- MRI might facilitate more detailed characterization of periapical lesions

- MRI might provide more accurate lesion dimensions as X-raybased methods

Citation Format:

- Geibel MA., Schreiber ES, Bracher AK et al. Assessment of Apical Periodontitis by MRI: A Feasibility Study. Fortschr Röntgenstr 2015; 187: 269-275

\section{Introduction}

$\nabla$

Apical periodontitis (AP) is mainly caused by bacterial inflammation. Through an inflamed root canal (pulpitis) or a deep gingival sulcus, bacteria can penetrate to the apical foramen and cause local infections. Apical periodontitis can be classified as an acute type with pain symptomatology and a chronic type without pain. Several studies have evaluated the type and incidence of periapical lesions in vivo $[1,2]$ and in vitro $[3,4]$ with different diagnostic methods. Nair et al. investigated 256 extracted teeth for identification of the incidence of abscess, granuloma, and radicular cyst. Their results showed an incidence of granuloma (50\%) and periapical abscess (35\%) and a surprisingly low incidence of cysts (15\%), which could be further categorized into a true apical cyst (acute) and an apical pocket cyst (chronic) building up after healing. In a comparative study between radiographic assessment and histological findings [4], the same group analyzed 114 specimens and revealed an insufficient concurrence of diagnosis between the two modalities, clearly indicating the need for improved in vivo diagnostic tools. Simon et al. [2] investigated the use of СВCT for the classification of periapical lesions. In direct comparison, the CBCT-derived diagnosis compared well with the biopsy-based diagnosis in the majority of the cases (75\%). However, in about $25 \%$ of the cases, CBCT failed to differentiate between cyst and granuloma, indicating the need for advanced in vivo imaging techniques.

In the current clinical routine, X-ray-based imaging is still the gold standard for the diagnosing and progression monitoring of periapical lesions. Chronic apical periodontitis can be identified in the X-ray image by the related root resorption, hypercementosis and osteitis. Acute lesions, however, are difficult to assess by $\mathrm{X}$-ray before substantial bone degeneration occurs.

Some studies have shown that a periapical lesion from endodontic infection might be present without being radiographically visible. In order to be radiographically visible, a periapical radiolucency should reach nearly $30-50 \%$ of bone mineral loss [5, $6]$. Furthermore, the size of periapical lesions is often underestimated in periapical radiographs [7-9].

The radiographic image conforms to a 2-dimensional projection of a 3-dimensional structure. The interpretation is known to be limited by complex background patterns such as overlapping roots and anatomic structures like maxillary sinus.

As a first step towards improved in vivo imaging, the increasing availability of cone beam computed tomography (CBCT) imaging systems enables volumetric imaging $[10,11]$. A few recent studies clearly indicate the potential improvement of the diagnosis of periapical lesions by the introduction of CBCT. In a comparison to conventional radiographs, Tsai et al. [12] and Liang et al. [13] proved a higher sensitivity of CBCT especially for smaller lesions and an overall increase in diagnostic fidelity. Estrela et al. [14] reported that only progressed periapical lesions were identified correctly by conventional radiography. In contrast, Balasundaram et al. [15] reported an only insignificant impact of CBCT diagnosis for the treatment of a respective lesion.

Due to the underlying physical principle, all X-ray (XR)-based imaging techniques have limited capabilities in soft tissue characterization and are supposed to be limited in the differentiation between chronic and acute periapical lesions that may have an impact on the treatment strategy. Furthermore, the related ionizing radiation with its well-known risks [16] limits the application of $\mathrm{CBCT}$ for longitudinal monitoring especially in young patients. Magnetic resonance imaging (MRI) has shown excellent results for soft-tissue visualization without any harmful radiation. Already in 1981, the versatile three-dimensional assessment of morphology and function raised the interest of MRI as a generic imaging tool in dental applications $[17,18]$.

However, up to now, only a few reports have been published on the application of MRI in dentistry mainly due to the limited access of dentists to MRI and limitations of MRI arising from metal artifacts caused by dental fillings. Without being used widely, reported applications of MRI in dentistry include the assessment of extracranial tumors [18-21], the assessment of the morphology and function of the temporomandibular joint [22 - 27], the planning of dental implantation procedures [28-32], planning and evaluating orthodontics and orthognathic surgery [33], the assessment of impacted teeth [34] and the mandibular and the trigeminal nerve channel [35-41], caries diagnosis [42-45], assessment of dental pulp [46,47], or for imaging of the mandible and mandibular for other purposes [ $48-50]$. With the introduction of faster imaging techniques that are less sensitive to dental filling material and the advent of new compounds, the application of MRI for periapical lesion diagnosis and characterization appears increasingly attractive and should be reconsidered.

It is the aim of this study to clinically evaluate the applicability of MRI for the assessment of apical periodontitis in direct comparison with $\mathrm{CBCT}$.

\section{Materials and Methods}

$\nabla$

19 consecutive patients (average age $43 \pm 13$ years) with 34 lesions in total (13 molars, 14 premolars and 7 front teeth) were enrolled in this feasibility study. XR findings included minor to severe periapical lesions. All patients had multiple dental fillings (including amalgam, gold, ceramic and composite fillings), crowns and bridges. As ferromagnetic materials containing alloys cause severe image artifacts in MRI, patients with retainers or brackets were excluded from this study. All patients under- 
went a CBCT scan and an MRI investigation within $16 \pm 15$ days. Two patients had to be excluded during the MRI scan due to severe claustrophobia.

The local ethics committee of the university approved the study protocol, and written informed consent was obtained from all patients before dental MRI.

\section{Imaging protocol}

The CBCT data were obtained on a wide volume imaging system (Galileos, Sirona Dental Systems, Germany) with an in-plane resolution of $0.287 \mathrm{~mm}$, a field of view of $150 \times 150 \times 150 \mathrm{~mm}^{3}$ and an effective average dose of $16-90 \mu \mathrm{Sv}$. All MRI data were acquired on a 3-Tesla whole-body system (Achieva 3 T, Philips Medical, Best, The Netherlands) with a 16-element neurovascular receive coil.

All patients underwent a standardized MRI protocol. After a first initial survey in axial, sagittal and coronal orientation, high-resolution (HR) scans were acquired in parasagittal or paracoronal orientation aligned with the central line of the teeth. The high-resolution diagnostic scans comprised a high-resolution multi-slice TSE acquisition (HR-TSE) with T1- (T1w) and T2-weighted (T2w) contrast. The scan time was 9:06 min (T1w) and 5:43 min (T2w). Relevant acquisition parameters are listed in Table I. Please note that the rather long repetition time of $T R=625 \mathrm{~ms}$ will not result in pure T1-weighted images, but the final image contrast will also be slightly impacted by the proton density. However, with average T1 values well above $1000 \mathrm{~ms}$ at a field strength of 3 T, T1 relaxation will still govern the resulting image contrast.

\section{Data analysis}

For analysis, all data were transferred to a medical workstation (ViewForum, Philips Healthcare, Best, The Netherlands). Periapical lesions were defined as periapical radiolucencies (CBCT) or structural changes in the spongy bone signal (MRI), which were connected with the apical part of a root and with at least twice the width of the periodontal ligament space.

Location and dimension of the lesions were compared between T1w, T2w images and CBCT. The isotropic CBCT data were reformatted in parasagittal direction similar to the MRI acquisition geometry. Lesion dimensions were independently quantified in either modality by their height $h$, width $w$ and area $A$ in the slice showing maximal extension of the lesion. All data were analyzed in consensus by an experienced dental radiologist (MAG, more than 20 years of dental radiology experience), a dental medical doctorate student (ESS, 1 year after approbation), an oral and maxillofacial surgeon (LKS, more than 10 years of experience), and an experienced MR scientist (VR, more than 20 years of MRI research experience). In this feasibility study, the data were not blinded for evaluation.

The correlation of the dimension measurement between the different approaches was assessed applying a Spearman's rho test and the significance of differences between measurements was assessed using the two-tailed paired student's t-test. Normal distribution of the data was tested by applying a Kolmogorov-Smirnov test. P-values below 0.05 were considered significant. All statistical analyses were performed with SPSS 21.0 (IBM Corp, Armonk, NY). In the case of invasive treatment, the excised material was histologically investigated for inflammation markers.

\section{Results}

$\nabla$

The imaging protocol was successfully performed in all investigated patients. The average MRI examination time for both sides including patient preparation and scan planning was 50 minutes. Although the patients presented with dental fillings, bridges and crowns, all lesions could be visualized with sufficient image quality. Even though a single acquisition took up to 9 minutes, no motion artifacts introduced by swallowing were observed. A typical example for the resulting image appearance with MRI in direct comparison with $\mathrm{CBCT}$ is presented in 8 Fig. 1. Where CBCT mainly shows mineralized tissue components such as teeth and bone, MRI provides complimentary information of the soft tissue components.

The T1w images ( $\bullet$ Fig. 1b) provide sufficient diagnostic detail for the assessment of the main structures of interest. The large lesion visible on CBCT images ( $\bullet$ Fig. 1a) can be clearly seen on the MR image. According to the imaging physics, the contrast be-
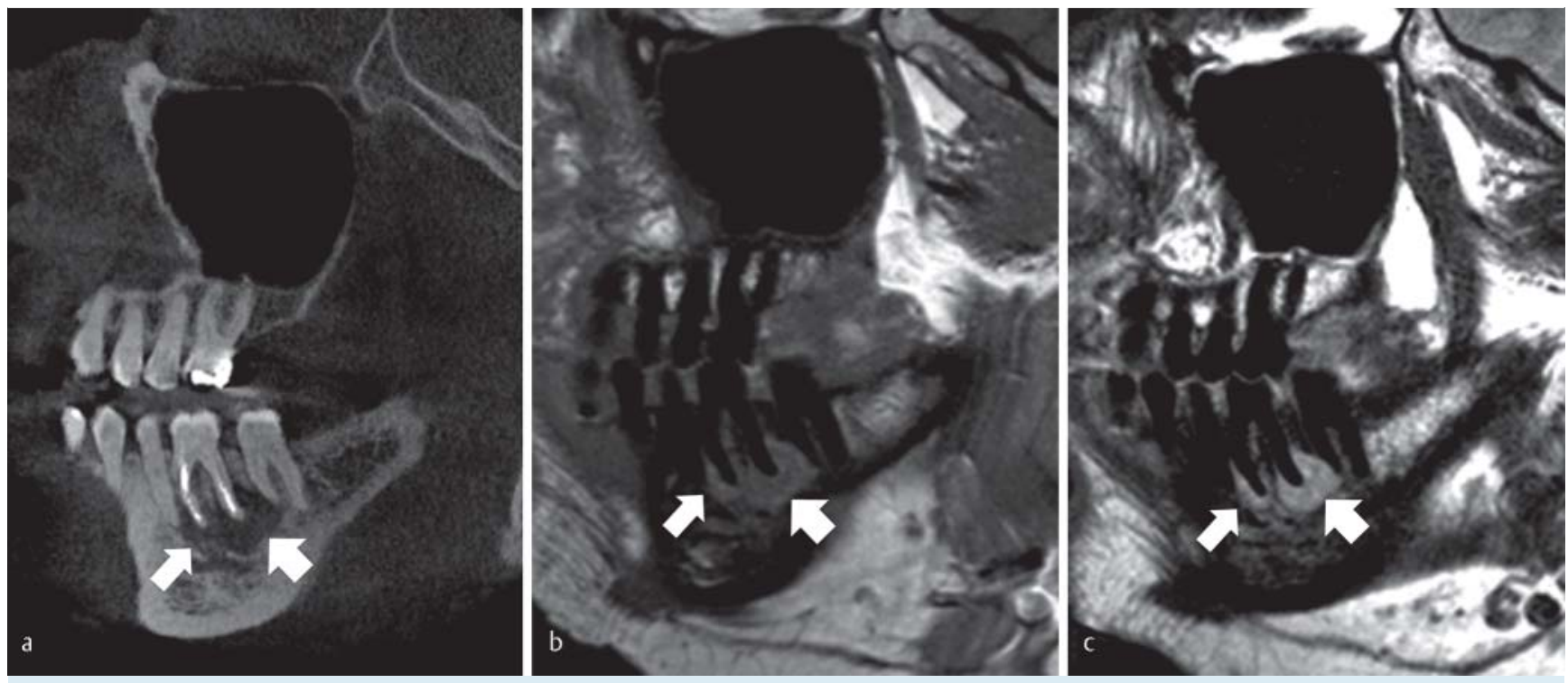

Fig. 1 Cystic lesion (arrow) - CBCT $\mathbf{a}$ and T1- $\mathbf{b}$ and T2- weighted MRI images $\mathbf{c}$

Abb. 1 Zystische Läsion (Pfeile) - DVT a und T1-b und T2 gewichteten MRT Daten c. 

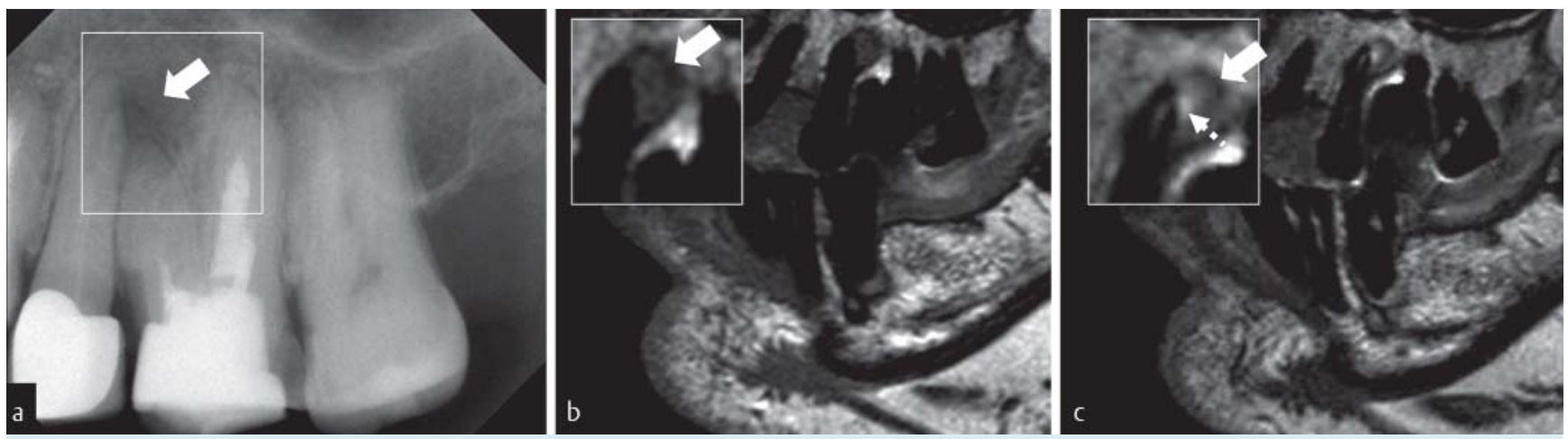

Fig. 2 Radicular cyst (arrow) - radiograph a, T1w MRI b, and T2w MRI c showing a clear enhancement at the location of the apical foramen (dashed arrow) in the T2w MRI images.

Abb. 2 Radikuläre Zyste (Pfeil) - Zahnfilm a, T1w MRT (B) und T2w MRT c einer apikalen Osteolyse (Pfeil) mit deutlicher Aufhellung in der Region des apikalen Foramens (gestrichelter Pfeil) in den T2w MRT Daten.
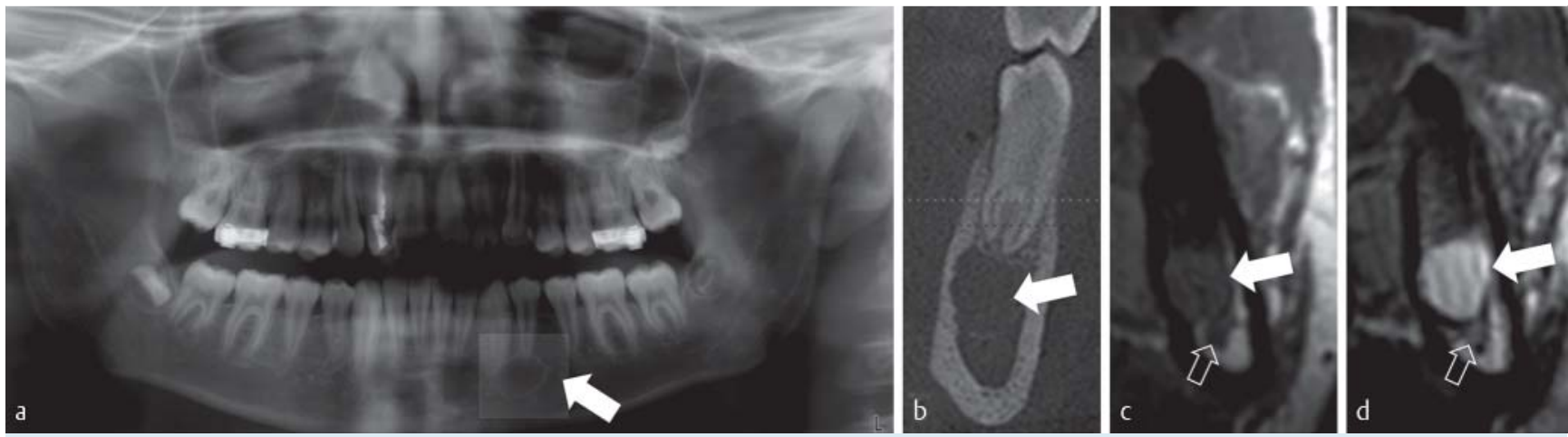

Fig. 3 Simple fluid-filled cavity (arrow): - OPG a, orthogonal reformatted CBCT $\mathbf{b}$, orthogonally acquired MRI located in the center of the lesion with $\mathrm{T} 1$ - $\mathbf{c}$ and T2-weighted $\mathbf{d}$ image contrast. Please note the close vicinity of the lesion to the root canal (open arrow), which can only be observed in the MR image.

Abb. 3 Flüssigkeitsgefüllter Raum (Pfeil) - OPG a, orthogonal zum Kieferkamm orientierte Schicht zentral durch die Läsion im DVT b und orthogonal zum Kiefer gemessene Schicht im MRT mit T1- c und T2- Wichtung d. Nur in der MRT Darstellung kann die enge Langebeziehung zum Wurzelkanal (offener Pfeil) eindeutig dargestellt werden.

tween the lesion and the surrounding mineralized material is inverted. Highly mineralized structures, appearing bright on CBCT images, result as signal voids in the respective MRI representation. However, due to the surrounding soft tissue (gingiva, muscle, salivary glands), and the bone marrow (high fat content), the cortical bone and the teeth can be clearly identified. In direct comparison, the lesion appears more homogeneous on the CBCT image. No apparent artifacts from the dental fillings occur in MRI, while some streaks caused by beam hardening can be observed on the CBCT images. Root filling materials, however, are not visible on the MRI images and the apical foramen cannot be directly assessed. The heterogeneous contrast within the lesion is even more obvious in the T2w image ( $\bullet$ Fig. 1c), with clear enhancement close to the apical foramen and the periodontal gap.

All lesions identified with CBCT were clearly visible on T1w as well as in T2w MR images. The lesion dimensions in T1w and T2w MRI corresponded well $\left(\mathrm{R}^{2}=0.98, \mathrm{p}<0.01\right)$ to each other and did not show any significant differences $\left(\mathrm{p}_{\mathrm{T1} 1 \mathrm{~T} 2}: \mathrm{w}>0.82, \mathrm{~h}>0.87, \mathrm{~A}>0.84\right)$. Compared with $\mathrm{CBCT}$, the lesion dimensions were slightly but significantly overestimated for T1w as well as T2w image contrast ( $\mathrm{p}_{\mathrm{T1}-\mathrm{DVT}}$ : $\mathrm{w}<0.01, \mathrm{~h}<0.01, \mathrm{~A}<0.01$; $\mathrm{p}_{\mathrm{T} 2-\mathrm{DVT}}$ : $\mathrm{w}<0.01, \mathrm{~h}<0.01, \mathrm{~A}$ $<0.01$ ). The correlation between MRI and CBCT data showed reasonably good results with values ranging between $R^{2}=0.73$ and
0.89 , all highly significant with p-values below 0.01 . A heterogeneous lesion appearance on the T2w MR images was observed in several patients and four patients presented with a well circumscribed hyperintense signal in the vicinity of the apical foramen (৫ Fig. 2). Only one of five clinically identified chronic lesions (four cysts and one granuloma, all showing inflammation markers in histology) showed a clear heterogeneous signal on T2w images. The dimension of the remaining lesions was too small to allow assessment of heterogeneous contrast.

In several cases, MRI could provide additional information not directly available from XR-based imaging. Exemplarily, Figs. 3 and 4 show two patients presenting with similar clinical symptoms and lesion appearance on the CBCT and OPG images. From the respective MR images, both cases could be clearly differentiated into a simple fluid-filled cavity ( $\bullet$ Fig. 3 ) and an encapsulated cyst ( $\bullet$ Fig. 4), which was confirmed by histology. Multi-contrast MRI especially helped with the identification of fluids ( $\mathrm{T} 1$ hypointense, $\mathrm{T} 2$ hyperintense) and fibrotic tissue (T1w and $\mathrm{T} 2 \mathrm{w}$ isointense). While the signal from fluids was hypointense on the T1w image when compared to fibrotic tissue, the contrast is inverted on the respective $\mathrm{T} 2 \mathrm{w}$ image, thus enabling identification of the cyst core and wall. 

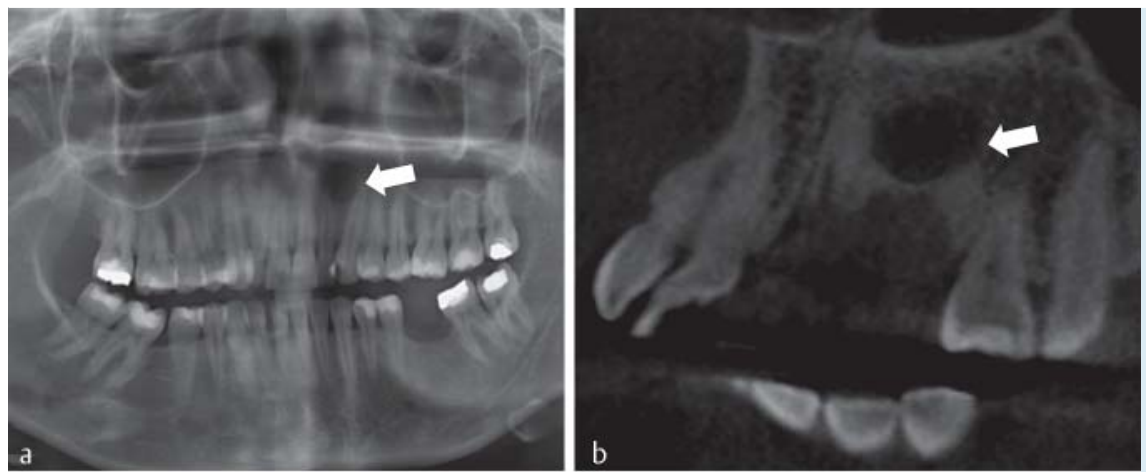

Fig. 4 Encapsulated cyst (arrow) - OPG a, CBCT b MRI with T1- $\mathbf{c}$ and T2-weighted $\mathbf{d}$ image contrast. In the MRI image, the lesions appears as fibrotically (open arrow, isointense in T1w and T2w) encapsulated fluid-filled (hypointense in T1w, hyperintense in T2w) space.

Abb. 4 Umschlossene Zyste (Pfeil) - OPG a, DVT b MRT T1-c und T2- gewichtetes MRT $\mathbf{d}$ der Läsion. In der MRT stellt sich die Zyste dar als fibrotisch (offener Pfeil, isointens in T1 und T2) umschlossener flüssigkeitsgefüllter Raum (hypointens im T1, hyperintens im T2) dar.
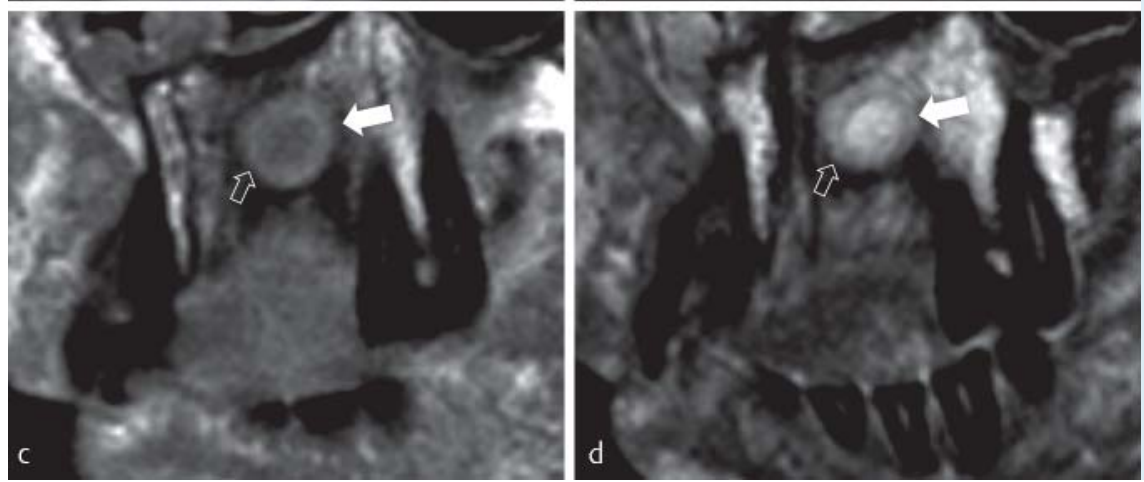

\section{Discussion \\ $\nabla$}

In oral and maxillofacial surgery, panoramic radiography is still considered to be the gold standard for examination of the dentomaxillofacial region. Although findings of apical osteolysis or cysts, especially in advanced cases, can sometimes be detected on radiographic images, superimposition of bony structures, dental roots, and filling materials, misinterpretation of artifacts, and the relatively low resolution capacity may cause pathological changes to go undetected [51] and demand the use of additional views. Furthermore, many radicular cysts remain asymptomatic and are incidentally discovered on a panoramic radiography image as possibly unsuspected disease. Using the conventional Xray techniques, it is not possible to distinguish a radicular cyst from a chronic apical granuloma, which may have an impact on the treatment regimen. Thus, the image quality of the panoramic radiography is clearly limited in its expressiveness and its use can only be justified by the low effective radiation dose [52].

To address these ambiguities, the investigators have moved along to three-dimensional imaging with CBCT $[13,14]$. Even on a CBCT scan, summation effects particularly occurring in the anterior region of the spinal column and the area of the palatal vault, have been shown to result in overlapping of root tips in the posterior region of the maxilla, thus the abovementioned issues partly come into play once more.

Even though magnetic resonance imaging (MRI) does not play a major role in current dental imaging, its potential for soft tissue characterization may raise interest especially in the imaging of periapical lesions. Concerns may arise from artifacts induced by dental fillings and also from limited assessment of the cortical bone.

This clinical study proves the applicability of conventional MRI sequences for the identification of periapical lesions. Comparing MRI to the standard CBCT scan used in daily clinical practice revealed a similar sensitivity in the diagnosis of periapical lesions. In the 19 patients randomly included in the study, no periapical lesion was missed due to metal artifacts on MRI, which was an issue for the authors in the beginning of the study.

However, significant differences in the lesion dimensions were observed between CBCT and MRI. One explanation might be the poorer spatial resolution of MRI compared to CBCT. However, we believe it is more likely that the overestimation on MR images resulted simply from the different physical principles behind these two modalities, since no differences were observed between the two investigated MRI sequences.

It has been shown $[5,6]$ that at least $30 \%$ mineral loss is required to detect a bony lesion on XR-based imaging methods. Instead, MRI can show the signal changes before substantial mineral loss occurs, due to its sensitivity to the changes in the number of water molecules in a given lesion $[43,44]$.

From the clinical routine it is well known that the lesion extent is often underestimated by XR-based methods, indicating only a limited performance in definition of the accurate lesion border. MRI may be able to assess the real extension of a lesion more accurately and thus provides a better estimation of the relationship of the lesion to the nearby critical structures such as the nerves and the vessels.

Advantages of MRI may further help in the field of lesion characterization. Due to its superior soft tissue contrast compared to $\mathrm{CBCT}$, the application of MRI may yield improved diagnostic information and pre-interventionally characterize the underlying pathology, which in turn affects the treatment regimen. This study focused on the comparison between CBCT and MRI regarding sensitivity and lesion dimensions. However even though destruction of the tumor structure during resection has so far precluded direct comparison between MRI appearance and histological tissue characterization, the presented data revealed strong evidence for the applicability of MRI for the delineation of different lesion types. Fujita et al. recently described the diagnostic value of MRI for the differentiation of certain odontogenic tumors [21]. Although the results were promising, one limitation of MRI has been shown to be its relatively low diagnostic ability for the assessment of the 
course of filled root canals. Where vital nerves in the root showed a bright MRI signal and could easily be assessed by MRI, the general nerve dehydration with aging and especially root canal fillings hindered identification of the root canal and the apical foramen. Whether this demands additional XR-based images remains to be shown in further clinical studies.

Although this study shows the feasibility of applying MRI for the imaging of periapical lesions, several obstacles have to be overcome before its wide clinical application. A major limiting factor is the intrinsically poor signal-to-noise ratio (SNR) of MRI. All data presented in this study were acquired on a high-field (3 T) whole-body clinical MR system. The likely drop in SNR may be addressed e.g. by usage of intraoral-coils [34], surface coils [37], or even dedicated dental phased-array coils [53]. The high imaging costs and long acquisition times still likely restrict the application of MRI to clinical research. To overcome these obstacles, dedicated dental systems enabling lower imaging costs, easier installation and maintenance, and more rapid data acquisition may be employed. While complete coverage of the entire jaw with high-definition T1 and T2 contrast was obtained in this study, the overall acquisition time could be significantly reduced by restricting the region of interest to the suspicious area. Rapid overview scans could be realized e.g. by applying fast T1-weighted $3 \mathrm{D}$ FLASH sequences enabling complete coverage of the jaw at isotropic spatial resolution in the minute range at slightly coarser spatial resolution, showing sufficient anatomic detail for the identification of culprit areas and enabling anatomically ideal reformats. By combining rapid overview imaging with subsequent high-definition local imaging of the culprit areas, substantial reduction of the overall scan time to the 15-minute range appears feasible.

Whether the required SNR values will be met by these systems and the quality of the images need to be further investigated.

Even though no severe limitations due to dental filling materials were observed in the present study, metal artifacts and image degradation cannot be completely excluded. Conductive materials will experience eddy currents, and the related magnetic field distortions likely cause signal cancelation in the proximity of the material, which may limit the application of the MRI e.g. in the presence of titanium implants. Ferromagnetic materials such as nickel and cobalt, which are frequently used in older alloys, dental prostheses, retainers and brackets, may also cause severe image degradation. However, compared to CBCT, MRI does not show long ranging banding and streaking artifacts, but only local image degradation, which is often restricted to the close proximity of the artifact source and does not impact neighboring teeth. The rather long acquisition times with MRI are prone to result in artifacts introduced by swallowing by the patient. Even though artifacts were not observed in this study, additional use of navigated MR sequences as used for high-resolution carotid imaging [54] may be required during larger clinical studies.

In summary, the identification of periapical lesions by means of MRI appears feasible. In comparison to the clinical standard, MRI may enable pre-interventional tissue characterization or at least an improved understanding of the lesion extent and pathology. Whether its limited spatial resolution, the prolonged acquisition time and the likely higher costs of imaging will prevent wide clinical application of the suggested technique is still unclear.

\section{References}

1 Trope M, Pettigrew J, Petras J et al. Differentiation of radicular cyst and granulomas using computerized tomography. Endodontics \& dental traumatology 1989; 5: 69-72 Epub 1989/04/01

2 Simon JH, Enciso R, Malfaz JM et al. Differential diagnosis of large periapical lesions using cone-beam computed tomography measurements and biopsy. Journal of endodontics 2006; 32: 833-877 Epub 2006/08/29

3 Nair PNR, Pajarola G, Schroder HE. Types and incidence of human periapical lesions obtained with extracted teeth. Oral surgery, oral medicine, oral pathology, oral radiology, and endodontics 1996; 81: $93-102$

4 Laux M, Abbott PV, Pajarola G et al. Apical inflammatory root resorption: a correlative radiographic and histological assessment. International endodontic journal 2000; 33: 483 - 493. DOI: Epub 2001/04/20

5 Bender IB, Seltzer S. Roentgenographic and direct observation of experimental lesions in bone I. J Am Dent Assoc 1961; 62: 152-160

6 Bender IB, Seltzer S. Roentgenographic and direct observation of experimental lesions in bone II. J Am Dent Assoc 1961; 62: 708 - 716

7 Shoha RR, Dowson J, Richards AG. Radiographic interpretation of experimentally produced bone lesions. Oral surgery, oral medicine, oral pathology, oral radiology, and endodontics 1974; 38: 294-303

8 Scarfe WC, Czerniejewski VJ, Farman AG et al. In vivo accuracy and reliability of color-coded image enhancements for the assessment of periradicular lesion dimensions. Oral surgery, oral medicine, oral pathology, oral radiology, and endodontics 1999; 88: 603-611 Epub 1999/11/11

9 Marmary Y, Koter T, Heling I. The effect of periapical rarefying osteitis on cortical and cancellous bone. A study comparing conventional radiographs with computed tomography. Dento maxillo facial radiology 1999; 28: $267-271$

10 Kottoor J, Velmurugan N, Sudha R et al. Maxillary first molar with seven root canals diagnosed with cone-beam computed tomography scanning: a case report. Journal of endodontics 2010; 36: 915-921 Epub 2010/04/27

11 Blattner TC, George N, Lee CC et al. Efficacy of cone-beam computed tomography as a modality to accurately identify the presence of second mesiobuccal canals in maxillary first and second molars: a pilot study. Journal of endodontics 2010; 36: $867-870$

12 Tsai P, Torabinejad M, Rice D et al. Accuracy of cone-beam computed tomography and periapical radiography in detecting small periapical lesions. Journal of endodontics 2012; 38: 965 - 970 Epub 2012/06/19

13 Liang YH, Jiang L, Gao XJ et al. Detection and measurement of artificial periapical lesions by cone-beam computed tomography. International endodontic journal 2014; 47: 332 - 338 Epub 2013/07/03

14 Estrela C, Bueno MR, Leles CR et al. Accuracy of cone beam computed tomography and panoramic and periapical radiography for detection of apical periodontitis. Journal of endodontics 2008; 34: $273-279$ Epub 2008/02/23

15 Balasundaram A, Shah P, Hoen MM et al. Comparison of cone-beam computed tomography and periapical radiography in predicting treatment decision for periapical lesions: a clinical study. International journal of dentistry 2012; 2012: 920815 Epub 2012/10/12

16 Claus EB, Calvocoressi L, Bondy ML et al. Dental X-rays and risk of meningioma. Cancer 2012; 118: 4530 - 4537 Epub 2012/04/12

17 van Luijk NMR. Dental imaging without $\mathrm{x}$-rays? Oral surgery, oral medicine, and oral pathology 1981; 52: $321-324$

18 Lam EW, Hannam AG, Wood WW et al. Imaging orofacial tissues by magnetic resonance. Oral surgery, oral medicine, and oral pathology 1989; 68: 2-8 Epub 1989/07/01

19 Tutton LM, Goddard PR. MRI of the teeth. The British journal of radiology 2002; 75: 552 - 562 Epub 2002/07/19

20 Avril L, Lombardi T, Ailianou A et al. Radiolucent lesions of the mandible: a pattern-based approach to diagnosis. Insights into imaging 2014; 5 : 85-101 Epub 2013/12/11

21 Fujita M, Matsuzaki H, Yanagi Y et al. Diagnostic value of MRI for odontogenic tumours. Dento maxillo facial radiology 2013; 42: 20120265 Epub 2013/03/08

22 Manfredini D, Guarda-Nardini L. Agreement between Research Diagnostic Criteria for Temporomandibular Disorders and magnetic resonance diagnoses of temporomandibular disc displacement in a patient population. International journal of oral and maxillofacial surgery 2008; 37: 612 - 616 Epub 2008/05/20

23 Helenius LM, Tervahartiala P, Helenius I et al. Clinical, radiographic and MRI findings of the temporomandibular joint in patients with differ- 
ent rheumatic diseases. International journal of oral and maxillofacial surgery 2006; 35: 983 - 989 Epub 2006/10/21

24 Sener S, Akganlu F. MRI characteristics of anterior disc displacement with and without reduction. Dento maxillo facial radiology 2004; 33: 245 - 252 Epub 2004/11/10

25 Chen YJ, Gallo LM, Meier D et al. Dynamic magnetic resonance imaging technique for the study of the temporomandibular joint. Journal of orofacial pain 2000; 14: 65-73 Epub 2001/02/24

26 Orhan K, Nishiyama H, Tadashi S et al. MR of 2270 TMJs: prevalence of radiographic presence of otomastoiditis in temporomandibular joint disorders. European journal of radiology 2005; 55: 102-107 Epub 2005/06/14

27 Tymofiyeva O, Proff P, Richter EJ et al. Correlation of MRT imaging with real-time axiography of TMJ clicks. Annals of anatomy = Anatomischer Anzeiger: official organ of the Anatomische Gesellschaft 2007; 189: 356-361 Epub 2007/08/19

28 Gray CF, Redpath TW, Smith FW. Magnetic resonance imaging: a useful tool for evaluation of bone prior to implant surgery. British dental journal 1998; 184: 603-607 Epub 1998/07/31

29 Gray CF, Redpath TW, Smith FW et al. Advanced imaging: Magnetic resonance imaging in implant dentistry. Clinical oral implants research 2003; 14: 18-27 Epub 2003/02/04

30 Makdissi J, Pawar RR, Radon $M$ et al. Incidental findings on MRI of the temporomandibular joint. Dento maxillo facial radiology 2013; 42: 20130175 Epub 2013/09/06

31 Aguiar MF, Marques AP, Carvalho AC et al. Accuracy of magnetic resonance imaging compared with computed tomography for implant planning. Clinical oral implants research 2008; 19: 362-365 Epub 2008/02/13

32 Imamura $\mathrm{H}$, Sato $\mathrm{H}$, Matsuura T et al. A comparative study of computed tomography and magnetic resonance imaging for the detection of mandibular canals and cross-sectional areas in diagnosis prior to dental implant treatment. Clinical implant dentistry and related research 2004; 6: 75-81 Epub 2005/01/27

33 Plooij JM, Maal TJ, Haers P et al. Digital three-dimensional image fusion processes for planning and evaluating orthodontics and orthognathic surgery. A systematic review. International journal of oral and maxillofacial surgery 2011; 40: 341 - 352 Epub 2010/11/26

34 Tymofiyeva O, Rottner K, Jakob PM et al. Three-dimensional localization of impacted teeth using magnetic resonance imaging. Clinical oral investigations 2010; 14: 169-176 Epub 2009/04/29

35 Krasny A, Krasny N, Prescher A. Anatomic variations of neural canal structures of the mandible observed by 3-tesla magnetic resonance imaging. Journal of computer assisted tomography 2012; 36: 150 153 Epub 2012/01/21

36 Krasny A, Krasny N, Prescher A. Study of inferior dental canal and its contents using high-resolution magnetic resonance imaging. Surgical and radiologic anatomy: SRA 2012; 34: 687-693 Epub 2011/12/07

37 Kress B, Gottschalk A, Anders L et al. High-resolution dental magnetic resonance imaging of inferior alveolar nerve responses to the extraction of third molars. European radiology 2004; 14: 1416-1420 Epub 2004/03/10

38 Nasel C, Gahleitner A, Breitenseher $M$ et al. Localization of the mandibular neurovascular bundle using dental magnetic resonance imaging. Dento maxillo facial radiology 1998; 27: 305 - 307 Epub 1999/01/08
39 Nasel C, Gahleitner A, Breitenseher M et al. Dental MR tomography of the mandible. Journal of computer assisted tomography 1998; 22 : 498 - 502 Epub 1998/06/02

40 Gottschalk A, Gerber S, Solbach T et al. Quantitative analysis of contrast enhanced MRI of the inferior alveolar nerve in inflammatory changes of the mandible. Fortschr Röntgenstr 2003; 175: 1344-1348 Epub 2003/10/14

41 Kress B, Rasche D, Fiebach J et al. MR volumetry of the trigeminal nerve in patients with unilateral facial pain. Fortschr Röntgenstr 2004; 176 : 719-723 Epub 2004/05/04

42 Tymofiyeva 0 , Boldt J, Rottner $K$ et al. High-resolution 3D magnetic resonance imaging and quantification of carious lesions and dental pulp in vivo. MAGMA 2009; 22: 365 - 374 Epub 2009/11/20

43 Bracher AK, Hofmann C, Bornstedt A et al. Feasibility of ultra-short echo time (UTE) magnetic resonance imaging for identification of carious lesions. Magnetic resonance in medicine: official journal of the Society of Magnetic Resonance in Medicine/Society of Magnetic Resonance in Medicine 2011; 66: 538-545 Epub 2011/03/02

44 Bracher AK, Hofmann C, Bornstedt A et al. Ultrashort echo time (UTE) MRI for the assessment of caries lesions. Dento maxillo facial radiology 2013; 42: 20120321 Epub 2013/02/20

45 Idiyatullin $D$, Corum C, Moeller $S$ et al. Dental magnetic resonance imaging: making the invisible visible. Journal of endodontics 2011; 37: 745-752 Epub 2011/07/27

$46 \mathrm{Kress} B, \mathrm{Buhl} Y$, Anders $L$ et al. Quantitative analysis of MRI signal intensity as a tool for evaluating tooth pulp vitality. Dento maxillo facial radiology 2004; 33: 241 - 244 Epub 2004/11/10

$47 \mathrm{Kress} B, \mathrm{Buhl} Y$, Hahnel S et al. Age- and tooth-related pulp cavity signal intensity changes in healthy teeth: a comparative magnetic resonance imaging analysis. Oral surgery, oral medicine, oral pathology, oral radiology, and endodontics 2007; 103: 134-137 Epub 2006/12/21

48 Gahleitner A, Nasel C, Schick S et al. Dental magnetic resonance tomography (dental MRI) as a method for imaging maxillo-mandibular tooth retention structures. Fortschr Röntgenstr 1998; 169: 424-428 Epub $1998 / 11 / 20$

49 Gahleitner A, Solar P, Nasel C et al. Magnetic resonance tomography in dental radiology (dental MRI). Der Radiologe 1999; 39: 1044-1050 Epub 2000/01/22

50 Gaudino C, Cosgarea R, Heiland S et al. MR-Imaging of teeth and periodontal apparatus: an experimental study comparing high-resolution MRI with MDCT and CBCT. European radiology 2011; 21: 2575-2583 Epub 2011/08/02

51 Hellstern F, Geibel MA. Quality assurance in digital dental radiographyjustification and dose reduction in dental and maxillofacial radiology. International journal of computerized dentistry 2012; 15: 35-44 Epub 2012/08/31

52 Schilling R, Geibel MA. Assessment of the effective doses from two dental cone beam CT devices. Dento maxillo facial radiology 2013; 42: 20120273 Epub 2013/02/20

53 Choe BY, Woo DC, Ahn HS. Dental rf coil, head-fixing unit, and magnetic resonance imaging system including same. US Patent. US20120288820 A1 2012

54 Bornstedt A, Burgmaier M, Hombach V et al. Dual stack black blood carotid artery CMR at 3T: application to wall thickness visualization. Journal of cardiovascular magnetic resonance: official journal of the Society for Cardiovascular Magnetic Resonance 2009; 11: 45 Epub 2009/11/12 